\title{
Transumbilical Laparoscopic Cholecystectomy with Additional Port: A Single Surgeon's Experience with 291 Cases
}

\author{
Ji Woong Hwang, M.D., Byoung Yoon Ryu, Ph.D. \\ Department of Surgery, Chuncheon Sacred Heart Hospital, Hallym University Medical Center,Chuncheon, Korea
}

\begin{abstract}
Purpose: Single-port laparoscopic cholecystectomy may result in postoperative complication in patients with cholecystitis. An additional right subcostal port could make laparoscopic surgery safe in these patients. We suggest the transumbilical laparoscopic cholecystectomy with additional port, which can be performed safely regardless of cholecystitis.
\end{abstract}

Methods: Consecutive 291 patients underwent transumbilical laparoscopic cholecystectomy in the Department of Surgery by a single surgeon. We have usually used the globe port in the transumbilical area and an additional right subcostal port.

Results: The mean operation time was 44.0 \pm 15.2 min (range: 20-140). The mean hospital stay after operation was $4.0 \pm 2.3$ days (range: $1-9)$. Postoperative complications were umbilical hernia $(n=7)$ and bile leakage $(\mathrm{n}=3)$. There was no in-hospital mortality.

Conclusion: Transumbilical laparoscopic cholecystectomy can be performed in patients with most of benign gallbladder disease. And, an additional right subcostal port could be helpful in ensuring safe transumbilical laparoscopic cholecystectomy, even in patients with cholecystitis.

Keywords: Laparoscopy, Cholecystectomy, Cholecystitis

This is an Open Access article distributed under the terms of the Creative Commons Attribution Non-Commercial License (http:/l creativecommons.org/licenses/by-nc/4.0/) which permits unrestricted non-commercial use, distribution, and reproduction in any medium, provided the original work is properly cited.
Received October 16, 2014

Revised 1st November 4, 2014 2nd December 15, 2014

3rd December 16, 2014

Accepted January 27, 2015

Corresponding author

Byoung Yoon Ryu

Department of Surgery, Chuncheon

Sacred Heart Hospital, Hallym

University Medical Center, Sakju-ro

77, Chuncheon 200-704, Korea

Tel: +82-33-252-9970

Fax: +82-33-243-6413

E-mail: byryu@hallym.or.kr

\section{INTRODUCTION}

Laparoscopic cholecystectomy (LC) became the gold standard operation for benign gallbladder disease. The advantages of LC include improved cosmetic results, less postoperative pain, and shorter recovery time compared with open cholecystectomy. ${ }^{1}$ Despite the excellent results of standard laparoscopic cholecystectomy, attempts to minimize the ports have continued.

Single-port laparoscopic cholecystectomy has the potential advantages of fast recovery and improved cosmetic results. ${ }^{2}$ However, most studies of single-port laparoscopic cholecystectomy do not involve "pure" single-port surgery, which requires a second port or puncture for traction of the gallbladder., ${ }^{1,-10}$ In addition, most of them excluded patients with a BMI> $30 \mathrm{~kg} / \mathrm{m}^{2}$, cholecystitis, and previous abdominal surgery. ${ }^{10,11}$

Herein, we suggest transumbilical laparoscopic cholecystectomy with an additional port can be performed safely regardless of cholecystitis.

\section{MATERIALS AND METHODS}

From February 2010 to October 2013, 302 patients underwent consecutive transumbilical laparoscopic cholecystectomy. All the operations were performed by a single surgeon. The retrospective data was collected and analyzed. Regardless of cholecystitis, a history of abdominal operation, and obesity, 
most patients with benign gall bladder disease were included in this study. Among them, nine patients were excluded as a result of conversion to open cholecystectomy due to severe inflammation and adhesion, and two patients were excluded for hidden malignancy of the gallbladder.

\section{Operative technique}

Under general anesthesia, the patients were placed in the supine position in the reverse Trendelenburg position, and the right side was rotated slightly upwards. A single vertical, 20$\mathrm{mm}$ incision was made by pulling out the umbilicus. After exposing the intra-abdominal cavity with the open technique, the Glove port was placed. A small-sized wound retractor was inserted into the wound. Afterwards, a standard surgical glove was placed, surrounding the external ring of the retractor, and one 11-mm trocar and two 5-mm trocars were inserted through the fingers of the glove by cutting the tips (Fig. 1).

The abdomen was insufflated to a continuous pressure of $12 \mathrm{mmHg}$. Another 5-mm port was inserted into the right subcostal space for the retraction of the gallbladder. The first assistant retracted the fundus of the gallbladder with a grasper by using an additional right subcostal port, and Calot's Triangle was exposed (Fig. 2). A $10-\mathrm{mm} 30^{\circ}$ flexible camera, an operator's dissector, and an articulated instrument were inserted into a peritoneal cavity via the umbilical glove port. After dissecting Calot's Triangle, the cystic duct and cystic artery were ligated by clips and divided. The specimen was extracted via the umbilical port site and placed in a free finger of the Glove port, and at the end of the operation the specimen was removed with the glove port together. Thus, a retrieval bag was not needed for the removal of the specimen.

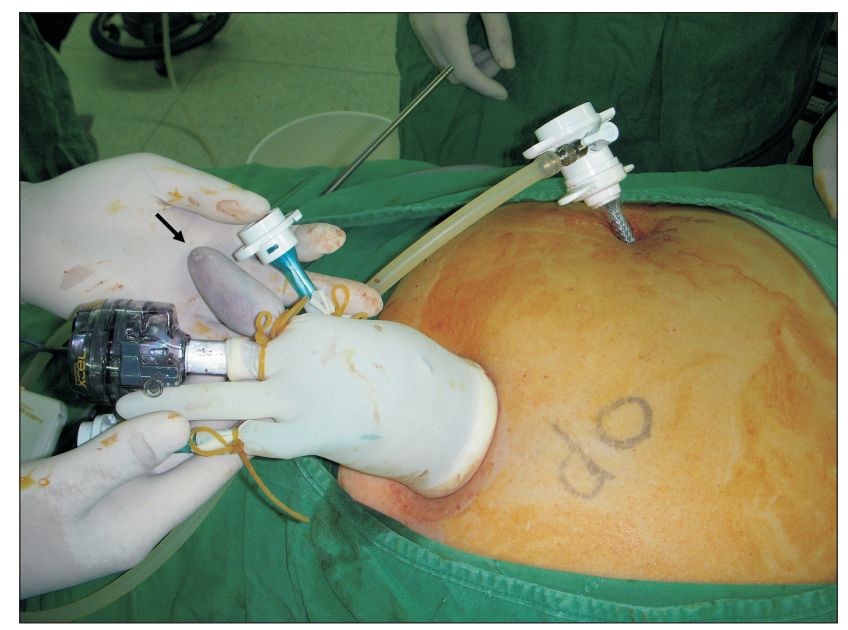

Fig. 1. Hand-made glove port and additional right subcostal port; gallbladder is placed in free finger of glove port (arrow).
The post-surgery scars are shown in Fig. 3.

The Fisher exact probability test was used as indicated for categorical variables, and continuous variables were compared with the Student's t-test. All data was expressed as the mean \pm standard deviation. Statistical significance was set at a $p$ value of less than 0.05. All analyses were performed using SPSS 21.0 (SPSS Inc., Chicago, IL, USA).

\section{RESULTS}

A total of 291 patients underwent transumbilical laparoscopic cholecystectomy; 125 men and 166 women were

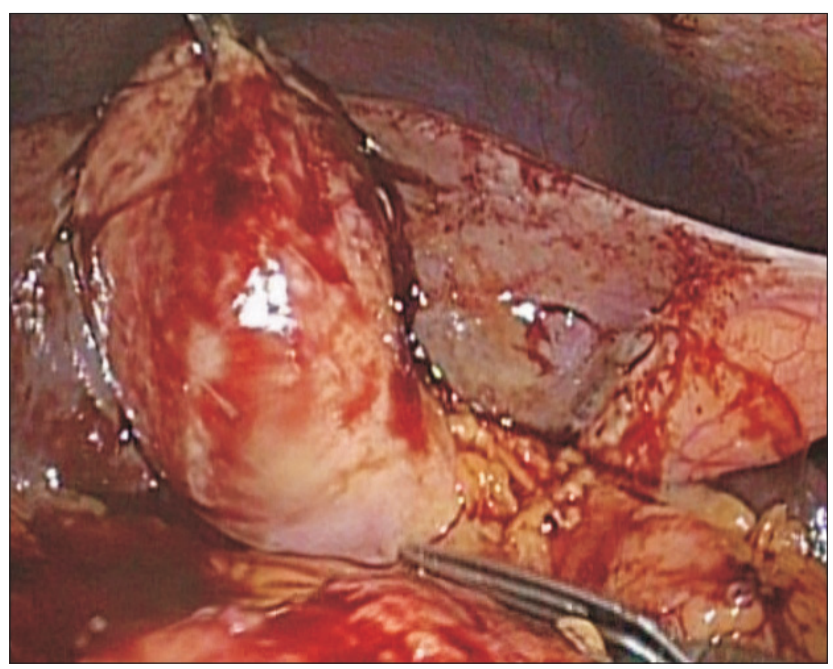

Fig. 2. Transumbilical laparoscopic cholecystectomy using additional right subcostal port; instrument via additional right subcostal port helps expose Calot's Triangle, even in cholecystitis.

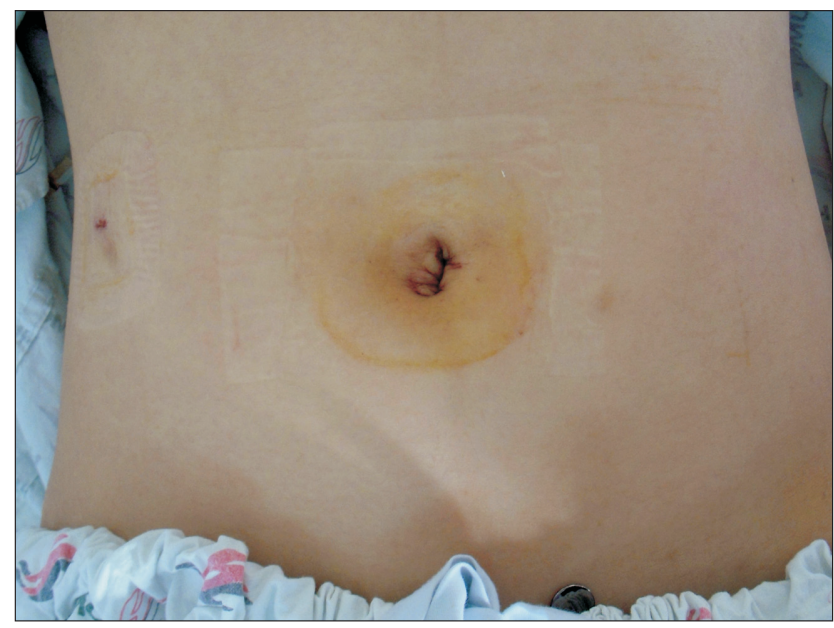

Fig. 3. Operative scars after transumbilical laparoscopic cholecystectomy. 
Table 1. The comparison of demographic characteristics with regard to the cholecystitis

\begin{tabular}{lccc}
\hline \multicolumn{1}{|c}{ Parameters } & $\begin{array}{c}\text { Without } \\
\text { cholecystitis } \\
(\mathbf{n}=208)\end{array}$ & $\begin{array}{c}\text { With } \\
\text { cholecystitis } \\
(\mathbf{n}=83)\end{array}$ & $p$ value \\
\hline Age (years) & $51.3 \pm 13.8$ & $52.12 \pm 16.5$ & 0.655 \\
$\begin{array}{l}\text { Gender } \\
\quad \text { Male }\end{array}$ & 85 & 40 & 0.254 \\
$\quad$ Female & 123 & 43 & \\
$\begin{array}{l}\text { Body mass index }\left(\mathrm{kg} / \mathrm{m}^{2}\right) \\
\quad<30\end{array}$ & 186 & 71 & \\
$\quad 30$ & 22 & 12 & \\
$\begin{array}{l}\text { Previous abdominal } \\
\text { operative history }\end{array}$ & & & 0.352 \\
Yes & & & \\
No & 47 & 15 & \\
\hline
\end{tabular}

included in this study. In the comparison of the demographic characteristics with regard to cholecystitis, no significant differences were found (Table 1). We determined the severity of cholecystitis based on the operative records (acute cholecystitis, $n=60$ [20.6\%]; chronic cholecystitis, $n=11$ [3.8\%]; acute gangrenous cholecystitis, $12[4.1 \%]$ ).

The mean operation time was $44.0 \pm 15.2$ min (range: $20-$ 140). The mean hospital stay duration after the operation was $4.0 \pm 2.3$ days (range: $1-9$ ). The postoperative complications were umbilical hernia $(n=7)$ and bile leakage $(n=3)$. There was no in-hospital mortality. Although the patients with cholecystitis needed longer operation time and postoperative hospital stays compared with the patients without cholecystitis, the rate of bile leakage was not significantly different between the two groups (Table 2).

\section{DISCUSSION}

Laparoscopic single-incision surgery has attracted wide attention due to the decreased number of incisions needed and superior cosmetic results. ${ }^{3}$ Some authors have suggested that laparoscopic single-incision cholecystectomy may become the gold standard treatment. ${ }^{12}$ However, most single-port laparoscopic cholecystectomy procedures were performed on selective patients without cholecystitis, obesity, and previous abdominal surgery, ${ }^{2,13,14}$ In addition, they still used ancillary instruments, such as a right upper quadrant suture passer, a Keith needle, a loop retractor, or an additional port. ${ }^{1,4,6,13,15,16}$

It is difficult to expose Calot's Triangle in "pure" singleport laparoscopic cholecystectomy. Therefore, most studies of single-port laparoscopic cholecystectomy used another
Table 2. The comparison of surgical outcomes according to the cholecystitis

\begin{tabular}{lccc}
\hline & $\begin{array}{c}\text { Without } \\
\text { cholecystitis } \\
(\mathbf{n}=208)\end{array}$ & $\begin{array}{c}\text { With } \\
\text { cholecystitis } \\
(\mathbf{n}=83)\end{array}$ & $p$ value \\
\hline Operative time & $41.6 \pm 12.9$ & $50.0 \pm 18.8$ & $<0.001$ \\
\hline Insertion of a drainage tube & $107(51.4 \%)$ & $62(74.7 \%)$ & $<0.001$ \\
\hline Hospital stay & $3.7 \pm 1.9$ & $4.7 \pm 2.9$ & 0.004 \\
\hline Postoperative bleeding & 0 & 0 & 1.000 \\
\hline Fluid collection & $2(0.9 \%)$ & $2(2.4 \%)$ & 0.338 \\
\hline Umbilical hernia & $6(2.9 \%)$ & $1(1.2 \%)$ & 0.677 \\
\hline Bile leakage & $1(0.5 \%)$ & $2(2.4 \%)$ & 0.204 \\
\hline Wound infection & $3(1.4 \%)$ & $4(4.8 \%)$ & 0.090 \\
\hline
\end{tabular}

The morbidity rates were not significantly different in whether cholecystitis or not in patients performed transumbilical laparoscopic cholecystectomy.

puncture or incision in the right subcostal space for retraction of the gallbladder by suturing or using an endo-loop. Furthermore, they applied these techniques only on patients without cholecystitis, because there are some limitations to handling a gallbladder with cholecystitis by using an endoloop or suturing. Thus, these methods can be performed in patients without cholecystitis, but not those with cholecystitis.

However, using an additional right subcostal port enables free manipulation of the gallbladder regardless of the incidence of cholecystitis by inserting a grasper or other instrument through this port. Consequently, transumbilical laparoscopic cholecystectomy can be safely applied in most cases of benign gallbladder disease, including severe cholecystitis.

We performed transumbilical laparoscopic cholecystectomy in 302 consecutive patients regardless of cholecystitis, obesity, and previous abdominal surgery. Among these patients, just nine patients (3.0\%) were conversed to exploration. The complications in this study occurred in 10 patients (3.4\%), which is acceptable considering the inclusion criteria, such as cholecystitis.

Umbilical trocar site hernia remained an unresolved task in transumbilical laparoscopic surgery. Many authors reported a higher rate of trocar site hernias in single-port laparoscopic cholecystectomy (from $2 \%$ to $12 \%$ ). ${ }^{2,17,18}$ Large fascia defects compared with the umbilical skin incision made secure fascia closure difficult. Seven patients (2.4\%) had a trocar site hernia in our study, which is a comparable outcome with that of other studies. ${ }^{19,20}$ All of these patients underwent hernia repair.

In conclusion, transumbilical laparoscopic cholecystectomy can be performed in most patients with benign gallbladder 
disease. Moreover, an additional right subcostal port could improve the safety of transumbilical laparoscopic cholecystectomy, even in patients with cholecystitis.

\section{REFERENCES}

1) $\mathrm{Hu} \mathrm{H}, \mathrm{Xu} \mathrm{AA}$, Huang A. Towards scarless surgery: a novel laparoscopic cholecystectomy by using 2-mm needle-shape instruments without trocar. J Laparoendosc Adv Surg Tech A 2013;23:698-701.

2) Marks JM, Phillips MS, Tacchino R, et al. Single-incision laparoscopic cholecystectomy is associated with improved cosmesis scoring at the cost of significantly higher hernia rates: 1-year results of a prospective randomized, multicenter, single-blinded trial of traditional multiport laparoscopic cholecystectomy vs single-incision laparoscopic cholecystectomy. J Am Coll Surg 2013;216:1037-1047; discussion 1047-1038.

3) Cheng Y, Jiang ZS, Xu XP, et al. Laparoendoscopic single-site cholecystectomy vs three-port laparoscopic cholecystectomy: a large-scale retrospective study. World J Gastroenterol 2013;19: 4209-4213.

4) Uras C, Boler DE. Endoloop retraction technique in single-port laparoscopic cholecystectomy: experience in 27 patients. J Laparoendosc Adv Surg Tech A 2013;23:545-548.

5) Ito $\mathrm{M}$, Asano $\mathrm{Y}$, Horiguchi $\mathrm{A}$, et al. Cholecystectomy using single-incision laparoscopic surgery with a new SILS port. J Hepatobiliary Pancreat Sci 2010;17:688-691.

6) Hirano $Y$, Watanabe $T$, Uchida $T$, et al. Single-incision laparoscopic cholecystectomy: single institution experience and literature review. World J Gastroenterol 2010;16:270-274.

7) Cao ZG, Cai W, Qin MF, Zhao HZ, Yue P, Li Y. Randomized clinical trial of single-incision versus conventional laparoscopic cholecystectomy: short-term operative outcomes. Surg Laparosc Endosc Percutan Tech 2011;21:311-313.

8) Zapf M, Yetasook A, Leung D, et al. Single-incision results in similar pain and quality of life scores compared with multiincision laparoscopic cholecystectomy: A blinded prospective randomized trial of 100 patients. Surgery 2013;154:662-671.

9) Uecker JM, Lopez DE. Single-incision Laparoscopic Cholecystectomy: No Benefit Over Conventional Laparoscopic
Cholecystectomy. Am Surg 2013;79:1227-1230.

10) Hwang HK, Choi SH, Kang CM, Lee WJ. Single-fulcrum laparoscopic cholecystectomy in uncomplicated gallbladder diseases: a retrospective comparative analysis with conventional laparoscopic cholecystectomy. Yonsei Med J 2013;54:1471-1477.

11) Carus $T$. Current advances in single-port laparoscopic surgery. Langenbecks Arch Surg 2013;398:925-929.

12) Vidal O, Valentini M, Ginesta $C$, et al. Single-incision versus standard laparoscopic cholecystectomy: comparison of surgical outcomes from a single institution. J Laparoendosc Adv Surg Tech A 2011;21:683-686.

13) Fronza JS, Linn JG, Nagle AP, Soper NJ. A single institution's experience with single incision cholecystectomy compared to standard laparoscopic cholecystectomy. Surgery 2010;148:731734; discussion 734-736.

14) Abdel Azeez T, Mahran KM. Transumbilical laparoscopic cholecystectomy: towards a scarless abdominal surgery. Hepatogastroenterology 2011;58:298-300.

15) Pan MX, Liang ZW, Cheng $Y$, et al. Learning curve of transumbilical suture-suspension single-incision laparoscopic cholecystectomy. World J Gastroenterol 2013;19:4786-4790.

16) Ikeda N, Ueno M, Kanamura $T$, et al. Safety and feasibility for single-incision laparoscopic cholecystectomy in local community hospital: a retrospective comparison with conventional 4-port laparoscopic cholecystectomy. Surg Laparosc Endosc Percutan Tech 2013;23:33-36.

17) Alptekin H, Yilmaz H, Acar F, Kafali ME, Sahin M. Incisional hernia rate may increase after single-port cholecystectomy. J Laparoendosc Adv Surg Tech A 2012;22:731-737.

18) Krajinovic K, Ickrath P, Germer CT, Reibetanz J. Trocar-site hernia after single-port cholecystectomy: not an exceptional complication? J Laparoendosc Adv Surg Tech A 2011;21:919-921.

19) Agaba EA, Rainville $H$, Ikedilo $O$, Vemulapali P. Incidence of port-site incisional hernia after single-incision laparoscopic surgery. JSLS 2014;18:204-210.

20) Yilmaz H, Alptekin H, Acar F, Calisir A, Sahin M. Single-incision laparoscopic cholecystectomy and overweight patients. Obes Surg 2014;24:123-127. 